Article

\title{
Study on the Curing Process of Silver Paste of Heterojunction Solar Cells Using Response Surface Methodology
}

\author{
Xin Li ${ }^{1}$, Hongyu Dong ${ }^{1}$, Shaoqing Guo ${ }^{2, *}$ and Liangfu Zhao ${ }^{1, *}$ \\ 1 Institute of Coal Chemistry, Chinese Academy of Sciences, Taiyuan 030001, China; lixin@sxicc.ac.cn (X.L.); \\ donghongyu@sxicc.ac.cn (H.D.) \\ 2 College of Environment and Safety, Taiyuan University of Science and Technology, Taiyuan 030024, China \\ * Correspondence: guosq@tyust.edu.cn (S.G.); lfzhao@sxicc.ac.cn (L.Z.)
}

Received: 23 June 2020; Accepted: 13 July 2020; Published: 15 July 2020

\begin{abstract}
Adhesion strength is of great importance for silver paste of heterojunction solar cells (HJT silver paste). It has a close relation with the curing system, as well as the curing process or curing conditions of the paste. The interactions among all the curing conditions such as curing time $(\mathrm{t}, \mathrm{min})$, treatment temperature $\left(\mathrm{T},{ }^{\circ} \mathrm{C}\right)$, and curing agent dosage $(\mathrm{m}, \mathrm{wt} \%)$ are obviously complex and hard to analyze. Response surface methodology (RSM) is used to research the interactions among $\mathrm{t}, \mathrm{T}$, and $\mathrm{m}$ and to optimize the curing process. The results of this study indicate that an increase of curing time and treatment temperature both had a positive effect on adhesion strength. The effect of curing time is more obvious under a lower treatment temperature. $41 \mathrm{wt} \%, 199^{\circ} \mathrm{C}$, and $44 \mathrm{~min}$ were determined as the optimum process conditions. The quadratic model predictions fitted well with the experimental data with a deviation less than $3 \%$. The FTIR results indicated that there were both addition and esterification processes in the reaction of E51 and ring-open MeTHPA. Scanning electron microscopy (SEM) images showed that the silver paste formed a dense interconnected network and provided a continuous pathway for current carrier transmission. This research demonstrated the effectiveness of the E51-MeTHPA system for HJT silver paste and the superiority of RSM in studying the curing process of silver paste.
\end{abstract}

Keywords: HJT silver paste; curing process; response surface methodology; adhesion strength

\section{Introduction}

The photovoltaic industry has experienced rapid development for several decades, owing to its environmental friendliness and renewability [1-5]. In recent years, many kinds of new methods have been proposed to prepare solar cells with excellent electrical performance [6-10]. Because of its high photoelectric conversion efficiency, low temperature coefficient, and low cost, the heterojunction solar cell (HJT solar cell) has been investigated by many scientific research institutions and companies [11-14]. During a typical manufacturing process for the HJT solar cell, intrinsic amorphous silicon, P-type amorphous silicon, and transparent conducting oxide film are deposited on $\mathrm{N}$-type silicon wafer in sequence and then silver paste is screen-printed on both sides as an electrode with a subsequent thermal curing treatment [15]. To avoid thermal damage to the amorphous silicon layer of the HJT solar cell, the process of thermal curing treatment after screen printing should be carried out at a low temperature of about $200{ }^{\circ} \mathrm{C}$. Consequently, the silver paste cured at low temperature should be used as the metal electrodes for the HJT solar cell, which is very different from traditional silver paste of crystalline silicon solar cells sintered at a higher temperature of about $800{ }^{\circ} \mathrm{C}$. For example, Heraeus Co., LTD. (Hanau, Germany), a silver paste commercial provider, developed a particular silver paste for HJT solar cells that could be cured at $200{ }^{\circ} \mathrm{C}$ [16]. 
Adhesion strength is one of the primary parameters of silver paste. It is an important symbol of soldering reliability, which affects the electrical performance and service life of the solar cell module. During the sintering process of traditional silver paste of crystalline silicon solar cells, silver particles in the paste are connected with each other by high-temperature fusing, and the glass phase in silver paste fuses and corrodes silicon wafer to form a stable ohmic contact, which presents a good soldering reliability $[17,18]$. However, for HJT silver paste, the treatment temperature is about $200{ }^{\circ} \mathrm{C}$, so that there is no sinter process at high temperature. The connections of silver particles to each other as well as the ohmic contact between Ag-HJT solar cells should be obtained by a new kind of curing system, which is mainly composed of organic binding agents, such as epoxy resin and a suitable latent curing agent. Increasing the mass fraction of the curing system in the HJT silver paste will improve the adhesion strength. However, a higher mass fraction of the curing system will reduce the electrical performance to some extent on account of the mass fraction of Ag decreasing. Meanwhile, the types of organic binding agents in the curing system also affect the adhesion strength as well as other characteristics of the HJT solar cell. Therefore, a high-performance curing system is indispensable to HJT silver paste, and it is necessary to investigate the curing mechanism and adjust the curing conditions of silver paste to improve the performance of the curing system and thus improve the adhesion strength of HJT silver paste.

It is obvious that the effects of curing conditions and the curing mechanism are of great significance to HJT silver paste to improve the adhesion strength. However, most of the experimental results concerning various curing systems were obtained with a single-factor method [19-21]. In this way, the interactions among those processing conditions are difficult to analyze. Especially, the dynamic effect of all the factors on the mechanical property of HJT silver paste cannot be determined.

Response surface methodology (RSM) is an experimental design method for multiparameter analysis with interaction determination, which is very effective to build statistically significant empirical models with a minimum number of experiments. Lai et al. demonstrated that RSM could be used for optimization of the preparation of silver powders with a model that accorded well with the experimental data [22]. Dennis et al. found that RSM could be used for predicting aluminum permeation with a model correlating with the experimental data [23]. Therefore, RSM shows the potential to analyze the interactions among the operation conditions as well as to determine the dynamic effect of all the factors on the mechanical property of the HJT silver paste.

The object of this work was to optimize the curing conditions of HJT silver paste and to build a model to evaluate the interactions among them by RSM. The processing conditions were curing time $(\mathrm{t}, \mathrm{min})$, treatment temperature $\left(\mathrm{T},{ }^{\circ} \mathrm{C}\right)$, and curing agent dosage $(\mathrm{m}, \mathrm{wt} \%)$. The optimization index was adhesion strength, which is an important index for paste property. Curing mechanism analysis and validation experiments were also carried out in this study.

\section{Materials and Methods}

\subsection{Materials}

Ag particles were purchased from Sino-Platinum Metals Co., LTD., Kunming, China. Tributyl citrate (98\%) and ethyl cellulose (90-110 mPa.s) were purchased from Aladdin Industrial Corporation, Shanghai, China. Terpineol (AR) was purchased from Zhiyuan Chemical Reagent Co., LTD, Tianjin, China. Diethylene glycol monobutyl ether was purchased from Panhua Industrial Limited Company, Shanghai, China. BYK-410 was purchased from BYK-Chemie Gmbh, Wesel, Germany. Epoxy resin E51 (epoxy value 0.48-0.54) and curing agent methyl tetrahydrophthalic anhydride (MeTHPA) were purchased from Lvxun Electronic materials Co., LTD, Kunshan, China.

\subsection{HJT Silver Paste Preparation and Curing}

HJT silver paste consists of Ag particles, organic solvent, and curing system. In this study, the proportion of the three main parts above were 80,13 , and $7 \mathrm{wt} \%$, respectively. The organic solvent 
was composed of terpineol (40 wt\%), tributyl citrate (32 wt\%), diethylene glycol monobutyl ether (22 wt\%), ethyl cellulose (90-110 mPa.s, $3 \mathrm{wt} \%$ ), and BYK-410 (3 wt\%).

The organic solvent was prepared in the following steps. All the liquid components were mixed by mass fraction. Then the mixture was heated to $60^{\circ} \mathrm{C}$ and then stirred. Afterwards, ethyl cellulose was added slowly to keep it from agglomerating. After all the ethyl cellulose was added, the mixture was continued to be stirred for $1 \mathrm{~h}$ until the mixture became uniform and the organic solvent was obtained.

The curing system was prepared as follows. First mix epoxy resin E51 and curing agent (MeTHPA) were prepared with a certain ratio. After stirring for $10 \mathrm{~min}$ at room temperature, the curing system was obtained.

The HJT silver paste was prepared by putting Ag particles, organic solvent, and curing agent into the sample bottle by mass fraction, and then the mixture was stirred for $20 \mathrm{~min}$ with a glass stirring rod at room temperature to make the Ag particles well distributed. The HJT silver paste was then obtained and ready to characterize.

\subsection{Characterization}

The adhesion strength was measured by an electronic tensile testing machine (CMT 6503, Sans Testing Machine Co., Ltd., Shenzhen, China).

Two pieces of partly overlapped stainless steel sheets $(100 \times 25 \times 2 \mathrm{~mm})$ were used as testing materials. The prepared HJT silver paste $(0.3 \pm 0.01 \mathrm{~g})$ was painted uniformly on the overlapping surface with a knife on each sheet, and the two sheets were pressed tightly. The size of faying surface was $25 \times 25 \mathrm{~mm}$. Then the two sheets were fixed with two clamps on both sides. After that, the sample was cured in an oven under air at experimental temperature. When the curing time was up, the sample was taken out and cooled down to room temperature for $2 \mathrm{~h}$ before testing. The maximum load of shear failure was measured with the electronic tensile testing machine. Adhesion strength was calculated by Equation (1):

$$
\tau=\frac{\mathrm{F}_{\mathrm{S}}}{\mathrm{A}}
$$

where $\tau$ is the adhesion strength of HJT silver paste (MPa), $F_{S}$ is the maximum failure load $(\mathrm{N})$, and $\mathrm{A}$ is the shear area of the samples $\left(\mathrm{mm}^{2}\right)$. When the shear area is constant, the adhesion strength can also be expressed by the maximum failure load.

Mechanism investigation experiments were performed using an FTIR spectrometer (Nicolet 380, Thermo Fisher Scientific, Waltham, MA, USA). The spectra were recorded at a resolution of $2 \mathrm{~cm}^{-1}$ in the range of $400-4000 \mathrm{~cm}^{-1}$. The microstructure of the paste before and after curing was analyzed by high-resolution scanning electron microscopy (SEM, JSM-7900F, JEOL, Kyoto, Japan).

\subsection{Experimental Design}

The experiments were designed by central composite design (CCD), which is part of the RSM to analyze the influences of the factors and the interactions among them. A quadratic model with several variables (the number of variables was more than 2 and less than 6) were built with CCD. Each variable had five levels: low $(-1)$, high $(+1)$, median $(0)$, and extreme $( \pm \alpha$, denoted as \pm 1.68 in this work) values. The extreme values were used to obtain a good prediction of the responses in this domain. The experimental values of factors (defined as $X_{i}$ ) were coded by Equation (2) to compare different factors with different units.

$$
\mathrm{A}_{\mathrm{i}}=\frac{\mathrm{X}_{\mathrm{i}}-\mathrm{X}_{0}}{\Delta \mathrm{X}}
$$

where $A_{i}$ is the coded value of the factor, $X_{0}$ defines the median value of the factor, and $\Delta X$ refers to the difference between the high and the median values of the factor.

In this study, curing time $(\mathrm{t})$, treatment temperature $(\mathrm{T})$, and curing agent dosage $(\mathrm{m})$ were analyzed as the variables (independent factors) and adhesion strength $(\mathrm{Y})$ as the response (dependent 
factor). The mass fraction of the three main parts of the HJT silver paste in this study were 80, 13 , and $7 \mathrm{wt} \%$, respectively, without specific reference.

Table 1 shows the coded and experimental values of $t, T$, and $m$. The experimental design in terms of coded values and the results are shown in Table 2. As can be seen in Table 2, the experiments were designed in terms of coded values. There are 19 runs designed in Table 2, which shows 9 experiments based on factorial design (Run no. 1-9), 4 experiments corresponding to the center to evaluate the errors (Run no. 10-13), and 6 experiments corresponding to the expansions (Run no. 14-19).

Table 1. Levels of investigated factors in this study.

\begin{tabular}{cccccc}
\hline \multirow{2}{*}{ Variable } & \multicolumn{5}{c}{ Level (Coded Value) } \\
\cline { 2 - 6 } & $\mathbf{- 1 . 6 8}$ & $\mathbf{- 1}$ & $\mathbf{0}$ & $\mathbf{1}$ & $\mathbf{1 . 6 8}$ \\
\hline $\mathrm{t}(\mathrm{min})$ & 30 & 34 & 40 & 46 & 50 \\
$\mathrm{~T}\left({ }^{\circ} \mathrm{C}\right)$ & 170 & 180 & 195 & 210 & 220 \\
$\mathrm{~m}(\mathrm{wt} \%)$ & 23 & 30 & 40 & 50 & 57 \\
\hline
\end{tabular}

Table 2. The experimental design in terms of coded values and the results.

\begin{tabular}{cccccc}
\hline \multirow{2}{*}{ Run No. } & \multicolumn{3}{c}{ Levels } & \multicolumn{3}{c}{ Adhesion Strength (Y, KPa) } \\
\cline { 2 - 6 } & $\mathbf{t}\left(\mathbf{X}_{\mathbf{1}}\right)$ & $\mathbf{T ~ ( \mathbf { X } _ { \mathbf { 2 } } )}$ & $\mathbf{m ~ ( \mathbf { X } _ { \mathbf { 3 } } )}$ & Experimental & Predicted \\
\hline 1 & -1 & 1 & 1 & 861 & 857 \\
2 & -1 & -1 & 1 & 470 & 463 \\
3 & -1 & -1 & -1 & 449 & 463 \\
4 & -1 & 1 & -1 & 857 & 857 \\
5 & 0 & 0 & 0 & 1131 & 1120 \\
6 & 1 & -1 & -1 & 627 & 642 \\
7 & 1 & -1 & 1 & 638 & 642 \\
8 & 1 & 1 & 1 & 832 & 823 \\
9 & 1 & 1 & -1 & 806 & 823 \\
10 & 0 & 0 & 0 & 1110 & 1120 \\
11 & 0 & 0 & 0 & 1108 & 1120 \\
12 & 0 & 0 & 0 & 1126 & 1120 \\
13 & 0 & 0 & 0 & 1121 & 1120 \\
14 & -1.68 & 0 & 0 & 873 & 876 \\
15 & 1.68 & 0 & 0 & 1011 & 999 \\
16 & 0 & 1.68 & 0 & 952 & 954 \\
17 & 0 & -1.68 & 0 & 482 & 471 \\
18 & 0 & 0 & 1.68 & 519 & 511 \\
19 & 0 & 0 & -1.68 & 511 & 511 \\
\hline
\end{tabular}

A quadratic model was used to reveal the relationships between the response and these variables (Equation (3)).

$$
\mathrm{Y}=\mathrm{b}_{0}+\sum_{\mathrm{i}=1}^{\mathrm{n}} \mathrm{b}_{\mathrm{i}} \mathrm{x}_{\mathrm{i}}+\sum_{\mathrm{i}=1}^{\mathrm{n}} \mathrm{b}_{\mathrm{ii}} \mathrm{x}_{\mathrm{i}}^{2}+\sum_{\mathrm{j}>1}^{\mathrm{n}} \sum_{\mathrm{i}=1}^{\mathrm{n}} \mathrm{b}_{\mathrm{ij}} \mathrm{x}_{\mathrm{i}} \mathrm{x}_{\mathrm{j}}
$$

where $Y$ is the response (adhesion strength); $b_{0}$ is a constant; $b_{i}, b_{i i}$, and $b_{i j}$ are the coefficients which reflect the linear, quadratic, and interaction relationship, respectively; $x_{i}$ and $x_{j}$ are the coded values of different factors ( $i$ and $\mathrm{j}$ vary between 1 and 3 in this study for $\mathrm{t}, \mathrm{T}$, and $\mathrm{m}$, respectively); and $\mathrm{n}$ is the number of independent factors. The CCD experimental design (Table 2) and data analysis were carried out using the software Design-Expert.

The significance test of the quadratic model was carried out through the analysis of the variance (ANOVA) and Fisher's F-test. A three-dimensional coordinate was used to show the relationships among different factors and the response in this work. 


\section{Results}

\subsection{Regression Models and Statistical Testing}

All the experiments were carried out in a random order to reduce systematic errors. Table 2 shows the results of the experiments, and a quadratic model was applied to fit the results with all the coefficients determined by using multiple regression analysis.

The relationship between adhesion strength and the factors were expressed through Equation (4) with significant terms in terms of coded values. The calculated values and experimental results are also shown in Table 2. The deviation between those calculated values and experimental results for adhesion strength were less than $3 \%$ (Figure 1 ).

$$
Y=1119.5+36.5 X_{1}+143.68 X_{2}-53.29 X_{1} X_{2}-64.3 X_{1}^{2}-144 X_{2}^{2}-215 X_{3}^{2}
$$

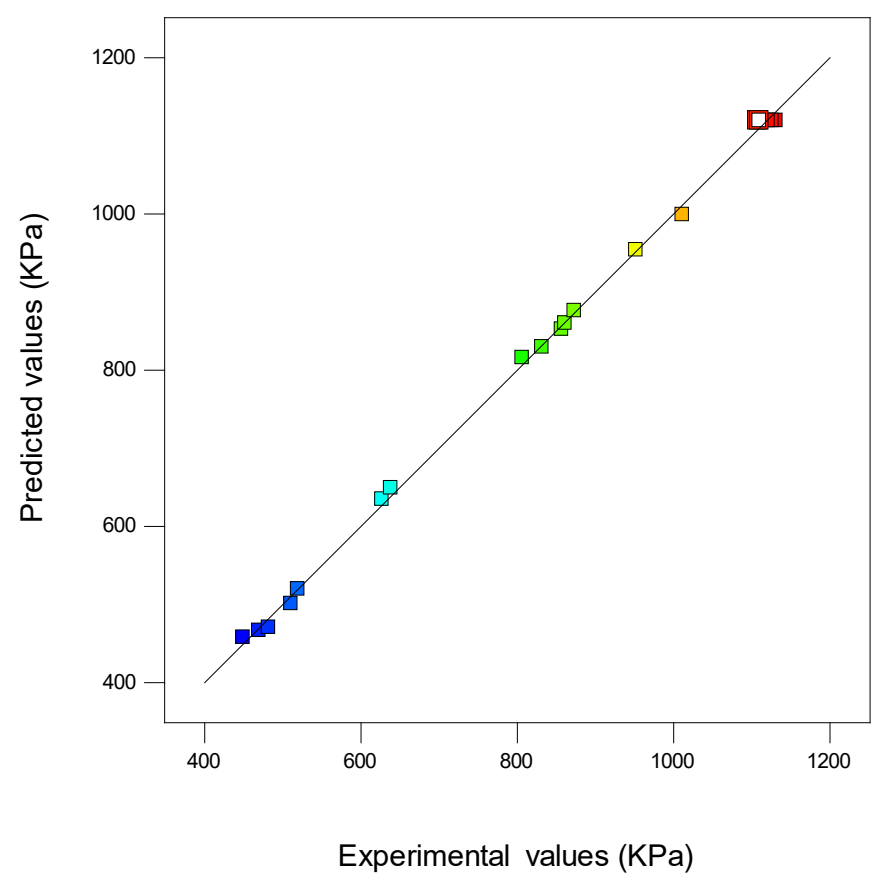

Figure 1. The relationship of calculated values and experimental values.

Table 3 shows the analysis of the variance of the quadratic model. The F-value of "Model" is 968.62, which implies that the model is significant. There is only a chance less than $0.01 \%$ that an F-value this large could occur due to noise. The values of "Prob $>\mathrm{F}^{\prime}$ less than 0.05 indicate that the model terms are significant and the values greater than 0.1 indicate that the model terms are not significant. It can be seen from Table 3 that all the variables (curing time, treatment temperature, and curing agent dosage) were significant for the response $Y$ as the values of $x$ or $x^{2}$ were less than 0.05 . The F-value of "Lack of Fit" is 1.48, which implies that the "Lack of Fit" is not significant relative to the pure error. There is a $36.24 \%$ chance that a "Lack of Fit F-value" this large could occur due to noise. The values of $R_{\text {adj }}{ }^{2}$ for the model is 0.997, which means that the experimental data agree with the quadratic model well. 
Table 3. Analysis of variance of the model regression for adhesion strength (Y).

\begin{tabular}{cccccc}
\hline Source & Sum of Squares & DF $^{\text {a }}$ & Mean Square & F-Value & $p$-Value Prob $>$ F \\
\hline Model & 113,7000 & 9 & 126,300 & 968 & $<0.0001$ \\
$\mathrm{x}_{1}: \mathrm{t}(\mathrm{min})$ & 18,229 & 1 & 18,229 & 139 & $<0.0001$ \\
$\mathrm{x}_{2}: \mathrm{T}\left({ }^{\circ} \mathrm{C}\right)$ & 281,900 & 1 & 281,900 & 2161 & $<0.0001$ \\
$\mathrm{x}_{3}: \mathrm{m}(\%)$ & 424.82 & 1 & 424 & 3.26 & $0.1046^{\mathrm{b}}$ \\
$\mathrm{x}_{1} \mathrm{x}_{2}$ & 22,716 & 1 & 22,716 & 174 & $<0.0001$ \\
$\mathrm{x}_{1} \mathrm{x}_{3}$ & 17.22 & 1 & 17.22 & 0.13 & $0.7247^{\mathrm{b}}$ \\
$\mathrm{x}_{2} \mathrm{x}_{3}$ & 0.40 & 1 & 0.40 & 3036 & $0.9573^{\mathrm{b}}$ \\
$\mathrm{x}_{1}{ }^{2}$ & 56,475 & 1 & 56,475 & 432 & $<0.0001$ \\
$\mathrm{x}_{2}{ }^{2}$ & 282,900 & 1 & 282,900 & 2168 & $<0.0001$ \\
$\mathrm{x}_{3}{ }^{2}$ & 633,000 & 1 & 633,000 & 4852 & $<0.0001$ \\
Residual & 1173 & 9 & 130 & & \\
Lack of Fit & 762.26 & 5 & 152 & 1.48 & $0.3624 \mathrm{~b}$ \\
\multicolumn{5}{c}{$\mathrm{R}^{2}=0.999 ; \mathrm{R}_{\mathrm{adj}}{ }^{2}=0.997 ;$ Adequate precision $=79.8$} & \\
\hline
\end{tabular}

${ }^{\mathrm{a}}$ Degree of freedom. ${ }^{\mathrm{b}} p$ value more than 0.05 indicates that the model terms are not significant.

\subsection{Effect of Variables on the Response}

The response surface of $\mathrm{Y}$ as a function of curing agent dosage $(\mathrm{m})$ and curing time $(\mathrm{t})$ is presented in Figure 2. It can be learnt from Figure 2 that the adhesion strength reached the maximum with a curing agent dosage of $40 \mathrm{wt} \%$. As stated above, the curing system used in the HJT silver paste consists of epoxy resin E51 and the curing agent MeTHPA. In actual fact, MeTHPA is a kind of reactive anhydride curing agent, which completes the curing process by reacting with epoxy resin in the curing system. Usually, the dosage of anhydride curing agent per $100 \mathrm{~g}$ epoxy resin is calculated by Equation (5):

$$
\mathrm{W}=\mathrm{M} \cdot \mathrm{E} \cdot \mathrm{K}
$$

where $\mathrm{W}$ is the dosage of curing agent per $100 \mathrm{~g}$ epoxy resin $(\mathrm{g}), \mathrm{M}$ is the molar mass of anhydride curing agent, $\mathrm{E}$ is the epoxy value of epoxy resin, which means the molar amount of epoxy group contained in $100 \mathrm{~g}$ epoxy resin, and $\mathrm{K}$ is an experimental coefficient (0.5-1.1). The experimental coefficient $\mathrm{K}$ is a key parameter for the curing process. Higher or lower mass fraction of MeTHPA will lead to excessive unreacted curing agent or epoxy resin left in the curing system, which causes a negative effect on the curing process and thus reduces the adhesion strength. The molar mass of MeTHPA (W) is 166.18; the epoxy value of E51 (E) is 0.51. In this E51-MeTHPA curing system, $\mathrm{K}$ can be calculated as 0.79 , based on the optimal curing agent dosage of $40 \mathrm{wt} \%$.

It can also be learnt from Figure 2 that the adhesion strength increased with the increase of curing time. After the curing time reached a certain level, the adhesion strength value tended to be constant. This is mainly because as the curing reaction proceeds, the crosslink density increases and the epoxy resin changes from a rubbery state to a glass state, hindering the molecule motion in the glass state. As a result, a further crosslinking reaction is difficult to reach [24].

The response surface of $\mathrm{Y}$ as a function of treatment temperature $(\mathrm{T})$ and curing time $(\mathrm{t})$ is presented in Figure 3. It demonstrates that there was a significant interaction of curing time and treatment temperature. The increase of curing time had a positive effect on adhesion strength when the treatment temperature was less than about $195^{\circ} \mathrm{C}$. For example, the adhesion strength increased by $26.4 \%$ (from 678 to $857 \mathrm{KPa}$ ) with an increasing curing time from 34 to $46 \mathrm{~min}$ at $180^{\circ} \mathrm{C}$. However, when the treatment temperature was under a higher level $\left(>195^{\circ} \mathrm{C}\right)$, the effect of the curing time was significantly weakened. The adhesion strength only increased by about 3\% (from 1038 to 1071 $\mathrm{KPa}$ ) with an increasing curing time from 34 to $46 \mathrm{~min}$ at $210{ }^{\circ} \mathrm{C}$. Generally, in the E51-MeTHPA curing system, the relationship between the reaction rate and temperature conforms to the Arrhenius formula [25]. It should be noted that, at relatively high temperatures, the curing reaction is completed 
quickly. Therefore, within the appropriate range, increasing the treatment temperature can shorten the curing time.

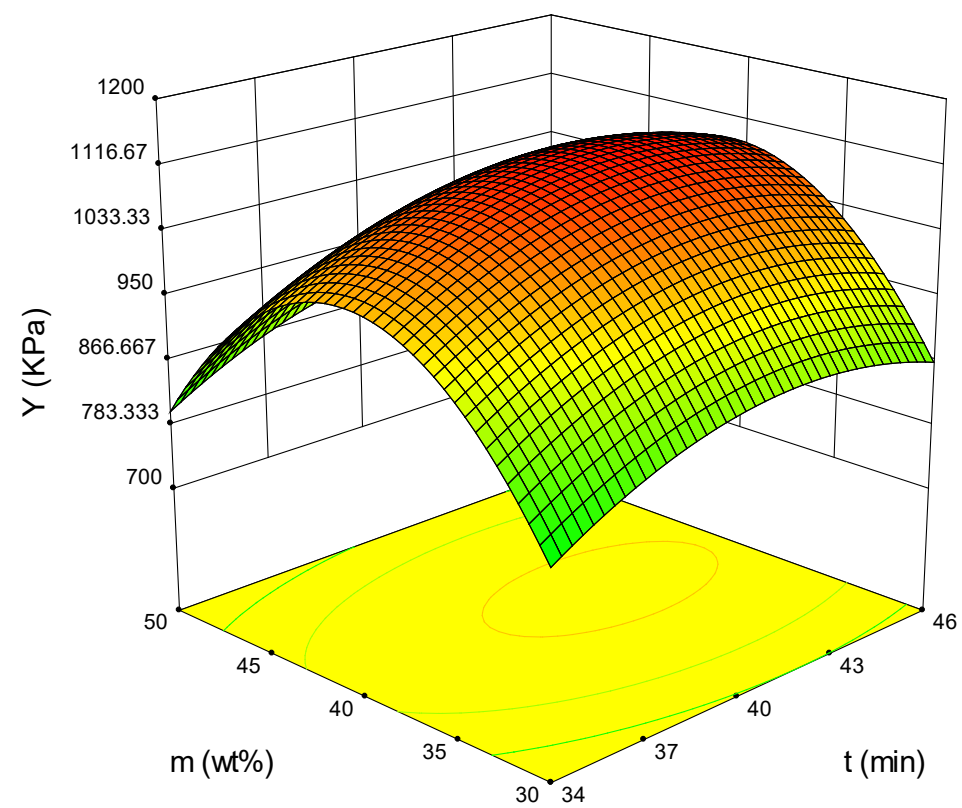

Figure 2. Response surface showing $\mathrm{Y}$ as a function of curing agent dosage $(\mathrm{m})$ and curing time $(\mathrm{t})$.

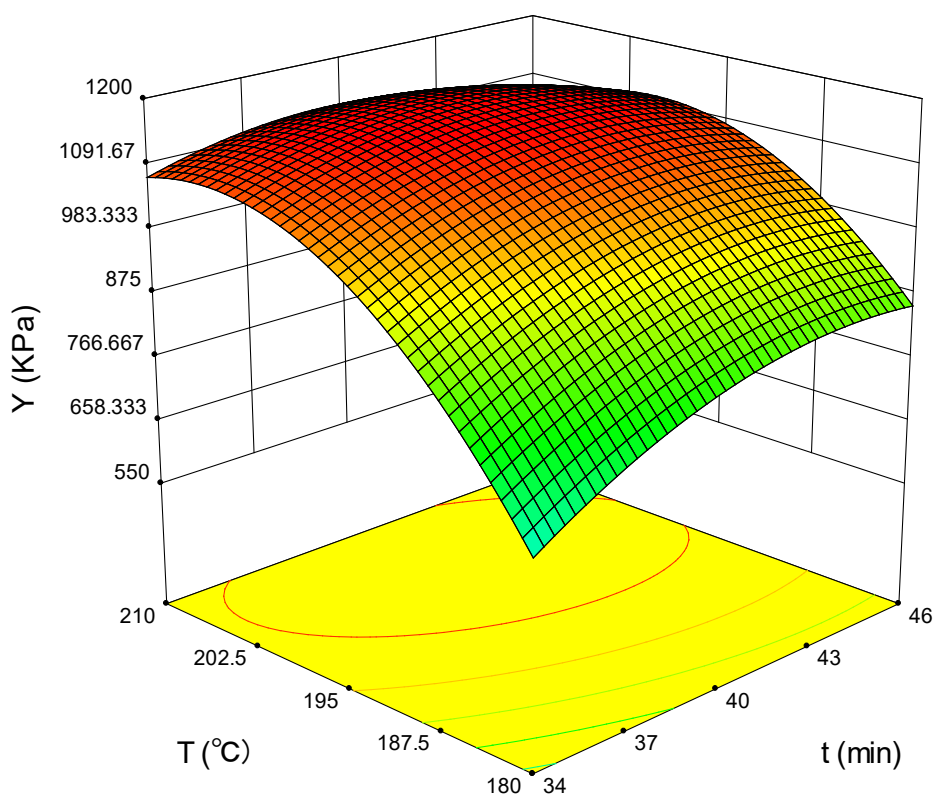

Figure 3. Response surface showing $\mathrm{Y}$ as a function of treatment temperature $(\mathrm{T})$ and curing time $(\mathrm{t})$.

The response surface of $\mathrm{Y}$ as a function of curing agent dosage $(\mathrm{m})$ and treatment temperature (T) is presented in Figure 4. As shown in Figure 4, the increase of treatment temperature led to the increase of adhesion strength at any curing agent dosage. When the treatment temperature reached above $200{ }^{\circ} \mathrm{C}$, the adhesion strength value tended to be constant. So, the increase of curing time and treatment temperature both had a positive effect on adhesion strength. According to the experimental results, and considering energy cost and the structural characteristics of the HJT solar cell, 195-200 ${ }^{\circ} \mathrm{C}$ and 35-45 min were the suitable treatment temperature and curing time of the HJT silver paste. $40 \mathrm{wt} \%$ was the suitable curing agent dosage according to the experimental results of Figure 2. 


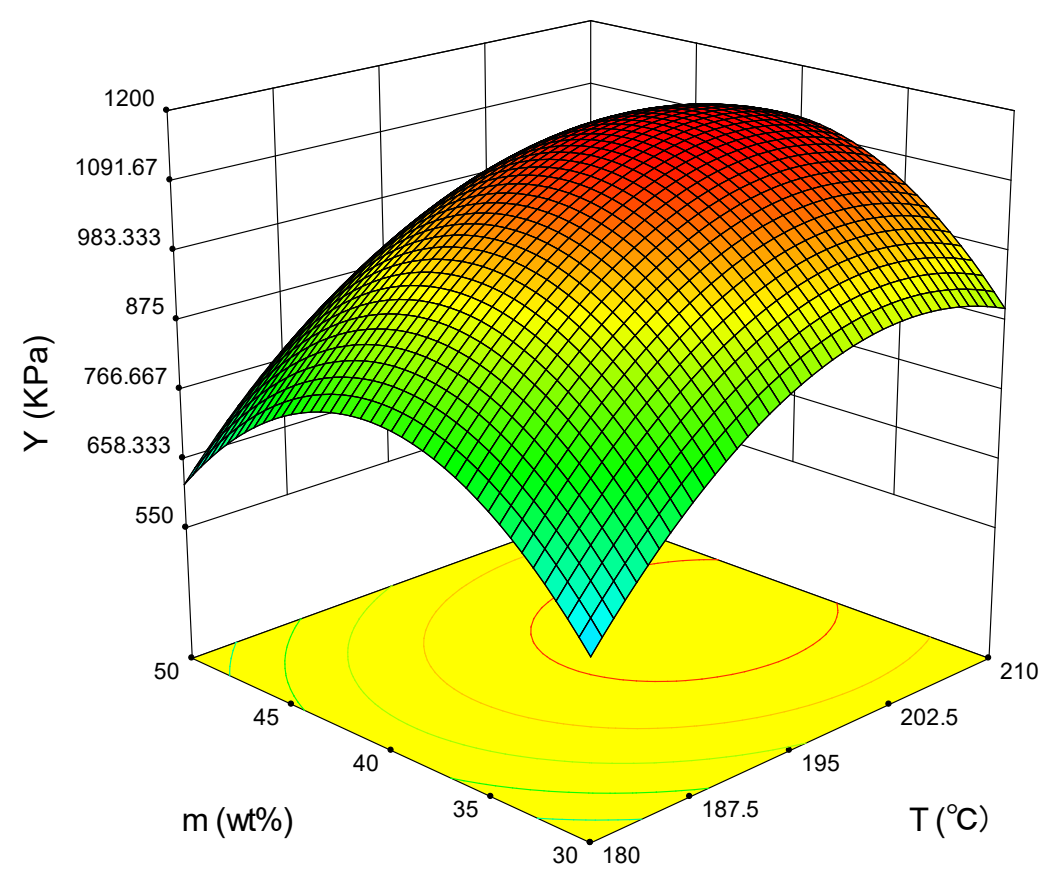

Figure 4. Response surface showing $\mathrm{Y}$ as a function of curing agent dosage $(\mathrm{m})$ and treatment temperature $(\mathrm{T})$.

\subsection{Optimization Experiment and Curing Mechanism}

The variables (operating conditions) can be optimized within the range of the experimental design using quadratic models to obtain higher $Y$ values. Three validation experiments were conducted with the optimized predicted operating condition to obtain the maximum value of $Y$ in the range of the experimental design. It is shown in Table 4 that the deviations between the results of three validation experiments and the predicted values were less than $2.2 \%$.

Table 4. Experimental and predicted values for adhesion strength $(\mathrm{Y})$ in the validation experiments.

\begin{tabular}{cccccc}
\hline \multirow{2}{*}{ No. } & $\mathbf{t}\left({ }^{\circ} \mathbf{C}\right)$ & $\mathbf{T}(\mathbf{M i n})$ & $\mathbf{M}(\mathbf{w t} \%)$ & Experimental Value & Predicted Value \\
\cline { 5 - 6 } & & & 41 & $\mathbf{Y ~ ( K P a )}$ & $\mathbf{Y}(\mathbf{K P a})$ \\
\hline 1 & 207 & 38 & 39 & 1145 & 1131 \\
2 & 198 & 42 & 41 & 1141 & 1131 \\
3 & 199 & 44 & 1156 & 1131 \\
\hline
\end{tabular}

To further investigate the curing mechanism of the E51-MeTHPA curing system, a FTIR spectrometer was used to observe the characteristic absorption band transformation at different time intervals. The curing reaction was carried out at $199{ }^{\circ} \mathrm{C}$ with the curing agent dosage of $41 \mathrm{wt} \%$ (the optimization experiment condition of No. 3 in Table 4).

The FTIR spectrogram at different curing times are shown in Figure 5. As the curing reaction proceeded, the characteristic absorption band of epoxy group (about $\left.915 \mathrm{~cm}^{-1}\right)$ and anhydride carbonyl group (1750-1824 $\mathrm{cm}^{-1}$ ) became weaker. This means that these functional groups were gradually reacted to form other materials during the curing process. The decreased intensity of the band at 976 and $1257 \mathrm{~cm}^{-1}$ (cyclic anhydride) indicated the ring-open process of anhydride during the reaction. At the same time, the characteristic absorption peak of the ester $\left(1740 \mathrm{~cm}^{-1}\right)$ and hydroxyl group (nearby $3500 \mathrm{~cm}^{-1}$ ) became stronger. This indicated that there were both addition and esterification processes in the reaction of E51 and the ring-open MeTHPA [25]. 


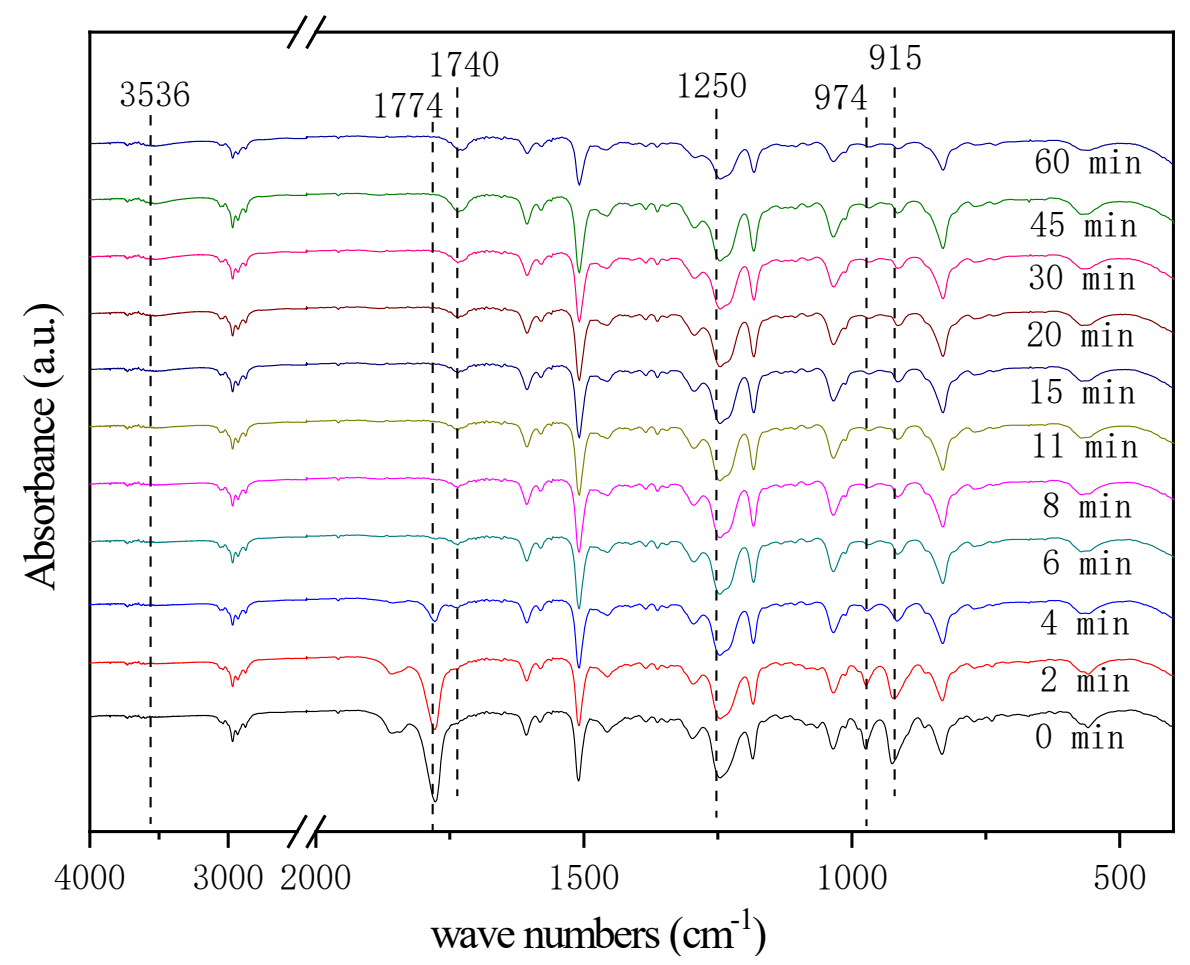

Figure 5. The FTIR spectrogram of the E51-MeTHPA curing system at different curing times $\left(\mathrm{T}=199^{\circ} \mathrm{C}\right.$, $\mathrm{m}=41 \mathrm{wt} \%)$.

A suitable curing time can also be determined by calculating the conversion rates of the epoxy group with the decreasing absorption band of the epoxy group at $915 \mathrm{~cm}^{-1}$. The band at $1609 \mathrm{~cm}^{-1}$ was attributed to the stretching vibration of $\mathrm{C}=\mathrm{C}$ in the benzene ring, which is invariable during the curing process. Therefore, it can be used as an internal standard peak. The conversion rate of the epoxy group is calculated by Equation (6):

$$
\delta_{\mathrm{t}}=\left[1-\frac{\left(\mathrm{A}_{915} / \mathrm{A}_{1609}\right)_{\mathrm{t}}}{\left(\mathrm{A}_{915} / \mathrm{A}_{1609}\right)_{\mathrm{t} 0}}\right] \times 100 \%
$$

where $\mathrm{A}$ is the peak area of corresponding wave number and $\mathrm{t}_{0}$ means the starting time. After $30 \mathrm{~min}$, the conversion rate was $84.3 \%$. The value became $93.6 \%$ at $45 \mathrm{~min}$. When the curing time reached $60 \mathrm{~min}$, the conversion rate was $95.3 \%$. The system was almost fully cured in $45 \mathrm{~min}$.

To clearly show the microstructure of the silver paste, the SEM images of the silver paste before and after curing have been taken and shown in Figure 6. The curing agent dosage of the paste was $41 \mathrm{wt} \%$. Figure 6A shows the surface image of the HJT silver paste before curing, and Figure 6B shows the surface image of the same silver paste after curing at $199{ }^{\circ} \mathrm{C}$ for $44 \mathrm{~min}$. It can be seen from Figure $6 \mathrm{~A}$ that a dense interconnected network was formed by Ag flakes, implying good contact between the flakes. From Figure 6B, it can be seen that the Ag flakes coalesced with each other and the neck formation was observed. This means that the silver paste after curing can provide a continuous pathway for current carrier transmission for solar cell. 

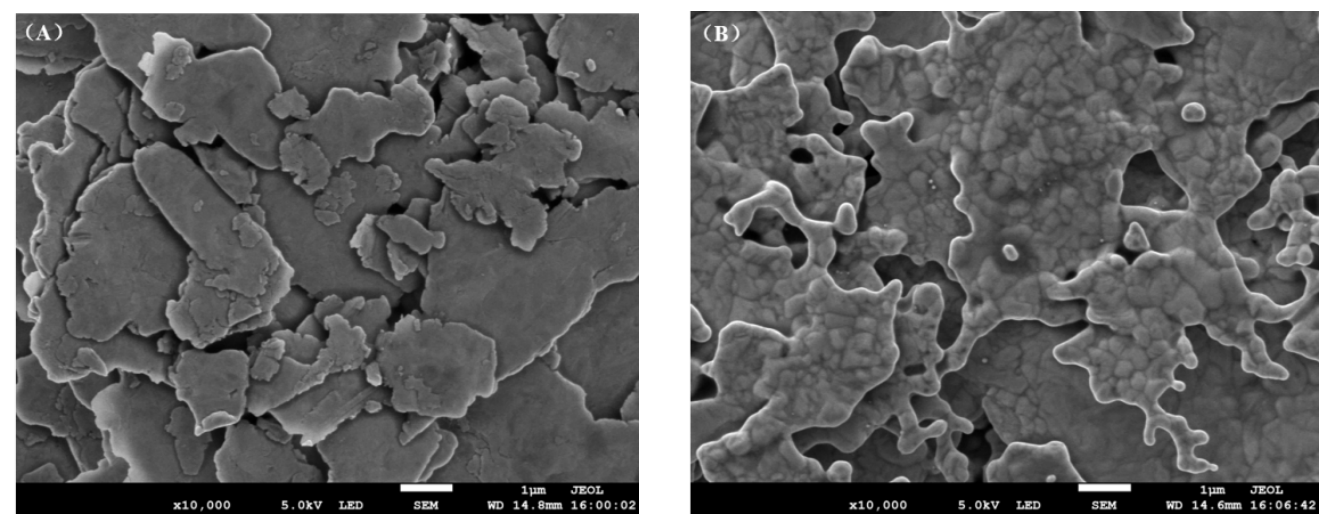

Figure 6. Microstructure of the heterojunction (HJT) silver paste with the curing agent dosage of $41 \mathrm{wt} \%$ : (A) before curing; (B) after curing at $199^{\circ} \mathrm{C}$ for $44 \mathrm{~min}$.

\section{Conclusions}

In this study, the effects of several process variables, including curing time $(t, \mathrm{~min})$, treatment temperature $\left(\mathrm{T},{ }^{\circ} \mathrm{C}\right)$, and curing agent dosage $(\mathrm{m}, \mathrm{wt} \%)$ on the adhesion strength of $\mathrm{HJT}$ silver paste were investigated. A response surface method was used to establish the quadratic models for the E51-MeTHPA curing system. Experimental results have shown that curing time and treatment temperature were both positively correlated with adhesion strength. The highest adhesion strength can be obtained under the optimum process conditions, i.e., the curing agent dosage of $41 \mathrm{wt} \%$, the curing time of $44 \mathrm{~min}$ and the treatment temperature of $199^{\circ} \mathrm{C}$. In summary, it can be concluded that the E51-MeTHPA curing system is a suitable curing system for HJT silver paste. Additionally, RSM is an effective way to optimize the various parameters of the curing process.

Author Contributions: Funding acquisition, review, and editing, L.Z.; investigation and experiment performance, X.L.; methodology, H.D.; writing—original draft, X.L.; software, writing—review and editing, S.G. All authors have read and agreed to the published version of the manuscript.

Funding: This research was funded by the Science and Technology Major Project of Shanxi Province (No. 20181101018), Bidding Project of Shanxi Province (20191101001, 202001101012), and the Key R\&D Project of Shanxi Province (201703D111008).

Conflicts of Interest: The authors declare no conflict of interest.

\section{References}

1. Aberle, A.G. Surface passivation of crystalline silicon solar cells: A review. Prog. Photovolt. 2000, 8, 473-487. [CrossRef]

2. Fang, H.; Wang, B.; Song, W. Analyzing the interrelationships among barriers to green procurement in photovoltaic industry: An integrated method. J. Clean. Prod. 2020, 249, 119408. [CrossRef]

3. Xin-gang, Z.; Zhen, W. Technology, cost, economic performance of distributed photovoltaic industry in China. Renew. Sustain. Energy Rev. 2019, 110, 53-64. [CrossRef]

4. De Souza, L.E.V.; Cavalcante, A.M.G. Towards a sociology of energy and globalization: Interconnectedness, capital, and knowledge in the Brazilian solar photovoltaic industry. Energy Res. Soc. Sci. 2016, 21, 145-154. [CrossRef]

5. Surek, T. Crystal growth and materials research in photovoltaics: Progress and challenges. J. Cryst. Growth 2005, 275, 292-304. [CrossRef]

6. Es, F.; Semiz, E.; Orhan, E.; Genç, E.; Kökbudak, G.; Baytemir, G.; Turan, R. Optimization of PERC fabrication based on loss analysis in an industrially relevant environment: First results from GÜNAM photovoltaic line (GPVL). Renew. Energy 2020, 146, 1676-1681. [CrossRef]

7. Liu, M.; Johnston, M.B.; Snaith, H.J. Efficient planar heterojunction perovskite solar cells by vapour deposition. Nature 2013, 501, 395-398. [CrossRef] [PubMed]

8. Chiu, J.; Zhao, Y.; Zhang, S.; Wuu, D. The role of laser ablated backside contact pattern in efficiency improvement of mono crystalline silicon PERC solar cells. Sol. Energy 2020, 196, 462-467. [CrossRef] 
9. Xu, J.; Yin, J.; Xiao, L.; Zhang, B.; Yao, J.; Dai, S. Bromide regulated film formation of CH3NH3PbI3 in low-pressure vapor-assisted deposition for efficient planar-heterojunction perovskite solar cells. Sol. Energy Mater. Sol. Cells 2016, 157, 1026-1037. [CrossRef]

10. Lee, Y.; El-Shall, H. Ultra-high aspect ratio titania nanoflakes for dye-sensitized solar cells. Appl. Surf. Sci. 2017, 426, 1263-1270. [CrossRef]

11. Breitenstein, O; Sontag, D. Lock-in thermography based local solar cell analysis for high efficiency monocrystalline hetero junction type solar cells. Sol. Energy Mater. Sol. Cells 2019, 193, 157-162. [CrossRef]

12. Lee, Y.; Kim, H.; Iftiquar, S.M.; Kim, S.; Kim, S.; Ahn, S.; Lee, Y.; Dao, V.A.; Yi, J. Study of stacked-emitter layer for high efficiency amorphous/crystalline silicon heterojunction solar cells. J. Appl. Phys. 2014, 116. [CrossRef]

13. Chen, D.; Zhao, L.; Diao, H.; Zhang, W.; Wang, G.; Wang, W. Low-temperature sintering properties of the screen-printed silver paste for a-Si:H/c-Si heterojunction solar cells. J. Mater. Sci. Mater. Electron. 2014, 25, 2657-2664. [CrossRef]

14. Liu, M.; Zhou, Y.; Dong, G.; Wang, W.; Wang, J.; Liu, C.; Liu, F.; Yu, D. SnO $2 / \mathrm{Mg}$ combination electron selective transport layer for Si heterojunction solar cells. Sol. Energy Mater. Sol. Cells 2019, 200, 109996. [CrossRef]

15. Chen, D.; Zhao, L.; Diao, H.; Zhang, W.; Wang, G.; Wang, W. Choice of the low-temperature sintering Ag paste for a-Si:H/c-Si heterojunction solar cell based on characterizing the electrical performance. J. Alloys Compd. 2015, 618, 357-365. [CrossRef]

16. Heraeus. Available online: https://www.heraeus.cn/media/media/hpt/doc_hpt/metallization_pastes_ downloads/2020_8/Spotlight_sol590-cn_2020.pdf (accessed on 19 June 2020).

17. Li, Y.; Gan, W.; Li, B. Silver nanoparticles-coated glass frits for silicon solar cells. Appl. Phys. A $2016,122$. [CrossRef]

18. Fu, M.; Cheng, S.; Wang, Y.; Zhou, H.; Fan, L. Effect of Te-Bi glass on the property of the front side silver electrode of crystalline silicon solar cell. J. Inorg. Mater. 2016, 31, 785-790.

19. Lin, T. The preparation and property study of low-temperature sintered silver-based paste for solar cell. Master's Thesis, Central South University, Changsha, China, 2014.

20. Zhang, D.; Wang, R.; Farhan, S.; Cai, Y.; Liu, J. Chemorheological behaviors of TDE-85 toughened by low viscosity liquid epoxy for RTM process. Polym. Test. 2018, 70, 310-319. [CrossRef]

21. Ramis, X.; Salla, J.M.; Mas, C.; Mantecon, A.; Serra, A. Kinetic study by FTIR, TMA, and DSC of the curing of a mixture of DGEBA resin and gamma-butyrolactone catalyzed by ytterbium triflate. J. Appl. Polym. Sci. 2004, 92, 381-393. [CrossRef]

22. Lai, Y.; Huang, H.; Huang, Q.; Zhang, H.; Guo, Z. Optimization of the experimental conditions for the synthesis of micro-size monodisperse spherical silver powders using Box-Behnken design. Powder Technol. 2014, 263, 7-13. [CrossRef]

23. Asante-Sackey, D.; Rathilal, S.; Pillay, V.L.; Tetteh, E.K. Effect of ion exchange dialysis process variables on aluminium permeation using response surface methodology. Environ. Eng. Res. 2020, 25, 714-721. [CrossRef]

24. Horie, K.; Hiura, H.; Sawada, M.; Mita, I.; Kambe, H. Calorimetric Investigation of Polymerization Reactions. III. Curing Reaction of Epoxides with Amines. J. Polym. Sci. 1970, 8, 1357-1372. [CrossRef]

25. Chen, P.Z.; Ni, H.; Xu, X.M. FTIR research of epoxy resin-MeTHPA curing system. J. Hubei Univ. 1989, 11, 57-60, 68 .

(C) 2020 by the authors. Licensee MDPI, Basel, Switzerland. This article is an open access article distributed under the terms and conditions of the Creative Commons Attribution (CC BY) license (http://creativecommons.org/licenses/by/4.0/). 